\title{
CHEMOTHERAPY AND THE VENEREAL DISEASES
}

\author{
R. R. WILLCOX, M.D. \\ Consultant Senior Assistant, Venereal Diseases Department, St. Mary's Hospital, London; Physician-in-Charge, \\ Venereal Diseases Clinic, King Edward VII Hospital, Windsor
}

G. M. Findlay ${ }^{10}$, in the preface to his authoritative Recent Advances in Chemotherapy, quotes the story in the Book of Tobit of the Angel Raphael who banished an evil spirit from Sara by means of a foul-smelling concoction. This, he states, was one of the earliest examples of the use of chemotherapeutic aerosols! Certainly chemotherapy has been employed for a very long time in the treatment of venereal disorders: for centuries mercury was used, sometimes even by inhalation, for the treatment of syphilis. Indeed, the first great advance towards modern methods followed Ehrlich's discovery of arsphenamine which, in an improved form in conjunction with bismuth, was for 30 years a most striking example of what could be achieved by chemotherapy.

When the sulphonamides were introduced in 1936, and obtained similar excellent results for gonorrhoea, the chemotherapeutic era for the venereal diseases was almost completely established. However, as a number of strains of the gonococcus were originally unresponsive, and others were made so by small doses of sulphonamides given for often trivial complaints, the resistant strains gradually became predominant. After only six or seven years in some places, e.g. Italy $^{5}$, gonorrhoea again became almost as great a problem as in pre-sulphonamide times. Then in 1943 came penicillin, and with it the simplest, safest and most effective treatment of gonorrhoea yet discovered and, with its application to the treatment of syphilis, this too became a safe and less time-consuming procedure.

During these early days it was thought that perhaps other potent antibiotics remained to be discovered and the research laboratories of the U.S.A. engaged teams of experts to find and test these as they were isolated. As the months went by and the new discoveries proved either too toxic or less effective, opinion swung the other way towards the view that penicillin was the most effective antibiotic, which by chance was also the first to be unearthed. Then came streptomycin, which was lethal to organisms previously untouched by penicillin. Since that time new antibiotics have appeared in bewildering profusion and one, chloramphenicol, has been synthesized. Those applicable to venereology are: penicillin from Penicillium notatum, streptomycin from Actinomyces griseus, aureomycin from :Streptomyces aureofaciens, chloromycetin (chloramphenicol) from Streptomyces venezuelae, and terramycin from Streptomyces rimosus.

Although it is likely that this small group of drugs can cure all of the venereal diseases, the sulphonamides, bismuth, and to a lesser extent the arsphenamines, are still being employed in their treatment; partly because the newer antibiotics are expensive and in short supply, and partly because many clinicians have been unwilling to plunge into the unknown without retaining a lifeline connecting with tried experience. With this overall picture in mind the most important of the venereal diseases will be considered separately.

\section{Gonorrhoea}

This disease is readily cured by penicillin, streptomycin, aureomycin, chloramphenicol and terramycin. Uncomplicated gonorrhoea, therefore, is no longer a therapeutic problem.

The general aim with all of the antibiotics is to maintain an effective serum level for six to eight hours. With less than this time there is the risk of failure and the possibility of breeding drug-fast strains, while with a longer time there is the theoretical danger of masking syphilis (i.e. should the patient contract syphilis at the same time as the gonorrhoea, the small dose of antibiotic given for the treatment of the latter disease might be insufficient for the syphilis and result in its appearance, perhaps in perverted form, after the patient is no longer under surveillance). Penicillin, aureomycin, chloramphenicol, and terramycin are all potent against $T$. pallidum, and the danger, therefore, exists with all. It is least with streptomycin but, even so, is not absent. The 
author has shown that syphilitic chancres will lose their spirochaetes after the administration of only r.5-6.0 g. of this drug ${ }^{45}$, although such will not occur after single doses of $0.6 \mathrm{~g} .{ }^{.2}$

On the other hand, this danger is probably overrated. In order to avoid it altogether, it has for some years been the practice in this country to follow up for a period of six months all patients with gonorrhoea who are treated with penicillin, instead of the three months which was usual with the sulphonamides, which drugs have no masking action upon syphilis. Few cases have in fact been revealed in which the usual incubation period of syphilis has been open to question and, as relatively few patients actually attend for six months anyway, the usefulness of this procedure is minimized. In fact Macfarlane ${ }^{24}$, after an analysis of 2,600 cases of gonorrhoea treated with penicillin, considers that a surveillance of three months is probably sufficient. Bauer ${ }^{2}$ states that there was little evidence of masked syphilis amongst demobilized American troops treated in the Forces for gonorrhoea. Willcox ${ }^{42}$ has examined the V.D. statistics of this country and by 1948 could find no evidence that syphilis was being masked but, to the contrary, that it was probably actually being cured during the incubation period. If the latter is once proven then it would be logical to treat gonorrhoea with larger doses of penicillin than we are using today. At present we adopt a kind of 'all or none' rule. As a routine we employ as small a dose as is necessary to cure the infection but, if complications dictate the giving of a higher dose, then it is logical to increase it sufficiently (e.g. to 2.4 mega units or more) so as a minimal curative dose for syphilis is given.

Adequate doses of the various drugs are, therefore, 300,000 units of procaine penicillin with or without 2 per cent. aluminium monostearate, $0.5-$ I.0 g. of streptomycin or dihydrostreptomycin, all by single injections. If the oral antibiotics are employed for those persons who fear the needle then 500,000 units of penicillin in buffered tablets may be given in a single dose, or the newer preparations, aureomycin, chloramphenicol and terramycin, may be employed. Although Greaves et $a .^{12}$ had 48 cured of 50 patients given single doses of $750 \mathrm{mg}$. of chloramphenicol, the results obtained with single doses of $\mathrm{I}$ gm. of aureomycin ( 56 cures in $70^{27}$ ), and terramycin ( 3 cures in $6^{28}$ ), have not been so satisfying. The method advocated by Hendricks et al. ${ }^{16}$ for terramycin might well be applied to all three of these drugs. That is to give two doses each of I gm. at an interval of six hours.

At the present stage of our knowledge penicillin is the best antibiotic to choose for routine purposes, except for those patients who dislike injec- tions and who may be given the orally administered drugs, and also for those patients in whom the risk of developing syphilis is higher than average. These latter include patients with acute gonorrhoea and phimosis in whom the sub-preputial condition cannot be adequately inspected, those with undiagnosed sores under observation, those with suspicious inguinal adenitis, and those with a history of intercourse with an infectious syphilitic. These patients should receive sulphonamides while the of dark field and serum tests are being performed: should this treatment be unsuccessful, as was the case in 176 of 205 patients treated in London by Dunlop in $1949^{8}$, then streptomycin in a single dose of $0.5 \mathrm{~g}$. may be used.

There is no great advantage in giving streptomycin instead of penicillin as a routine, as the somewhat smaller risk of masking syphilis is $\dot{\omega}$ offset by the possibility of encouraging drug-fast $\vec{O}$ strains which may so easily be fostered with this drug. In addition, an injection of streptomycin is somewhat more painful than penicillin. If used, 을 however, the results are satisfactory. For example, Taggart et al. ${ }^{32}$ had 95 of ro4 cured with as little as $0.2-0.4 \mathrm{~g}$. of dihydrostreptomycin.

\section{Granuloma Inguinale}

This world-wide disease, which has bee described as the enfant terrible of the Souther⿳亠口冋. United States, is a chronic debilitating condition producing genital or near genital granulomatous ulceration, often a similar condition in the groins arising from lesions below the skin (pseudobuboes), and occasional metastatic spread. The causative organism is Donovania granulomatis, which may be seen in scrapings from the lesions and resemble closed safety-pins, being found in the large mononuclear cells. The disease is encountered in Great Britain extremely rarely.

Until recently it was treated with antimonials on a regime reminiscent of the older treatments of syphilis. This was fairly effective, although resistant cases were not infrequently encountered and a considerable proportion relapsed. The situation was unchanged by the introduction of both the sulphonamides and penicillin, although $\frac{D}{0}$ the latter has been found useful in clearing the secondary infection in patients with super-added $\stackrel{N}{\circ}$ fuso-spirochetosis.

Greenblatt and his group ${ }^{13}$ have perhaps the $N$ greatest experience of the treatment of granuloma $\underset{\sigma}{\sigma}$ inguinale with antibiotics. Their published series now exceeds 142 cases treated with streptomycin, 46 with aureomycin, while 23 cases have been $\stackrel{\oplus}{\oplus}$ treated with chloramphenicol. Streptomycin given ? as $4 \mathrm{~g}$. daily for five days has proved most successful, as the author can testify, having employed $\stackrel{\overrightarrow{\mathbb{D}}}{\mathbb{D}}$ it on a number of patients in Southern Rhodesia. ${ }^{43} \stackrel{\mathrm{P}}{\mathrm{D}}$ 
The principal disadvantage of treatment with streptomycin is that admission to hospital is necessary. Aureomycin in doses of $2 \mathrm{~g}$. daily for . Io to 15 days is also most effective and may be given to out-patients, although gastro-intestinal side-effects and those of vitamin-B deficiency may occur. Greenblatt ${ }^{13}$ considers that chloramphenicol in the same dosage is less toxic than aureomycin and recommends its priority for outpatients.

\section{Lymphogranuloma Venereum}

This virus disorder, characterized by buboes in the male and by proctitis and rectal stricture in the female, is seldom seen in Great Britain except occasionally in the sea ports. In the past it has been fairly well controlled by the sulphonamides, although the virus has been shown to persist in patients showing apparent clinical cure. In 1948 Wright et al. ${ }^{53}$ demonstrated that aureomycin was effective in this condition, and this has been supported on small numbers of cases by various authors ${ }^{44}$. Recent more critical examination, however, on larger series of $\operatorname{cases}^{29}{ }^{36}$ has not been so encouraging. Greenblatt and his group ${ }^{13}$ consider that aureomycin is relatively ineffective in early cases but useful in large doses in late, usually female, cases with proctitis. The same workers consider that chloramphenicol is even less useful. Streptomycin is not effective although penicillin in large doses may be so in the early case with climatic bubo. ${ }^{38}$

At the present time the recommended treatment consists of sulphonamides given over a period of at least one week. Those cases which do not respond may be given oral aureomycin $2 \mathrm{~g}$. daily for 10 to 15 days.

\section{Non-specific Urethritis}

As gonorrhoea is now cured so easily, and the incidence of syphilis in Britain is declining, nonspecific urethritis is in many respects the most troublesome condition seen in the male venereal diseases clinic. Whereas in pre-chemotherapeutic times the physician commiserated with the patient when gonococci were found in his urethral smear, summarily dismissing him when they were not, the reverse is almost true today. Now the patient may be congratulated on the discovery of the gonococcus so rapid is the cure, but with a nongonococcal urethritis the prognosis is more guarded.

The causes of non-gonococcal urethritis are legion. Harkness (1950) ${ }^{15}$ is to be praised for so ably presenting them in his monograph. Apart from those cases caused by definite specific causes, perhaps the major number are those of abacterial urethritis, in which virus inclusion bodies and/or pleuro-pneumonia-like organisms may be found in scrapings from the urethra. Exactly the relationship between these two with each other, if any, or indeed with the urethritis itself, is not yet completely understood although there are good reasons to believe that the commoner cause is that of a. virus.

Many chemotherapeutic substances have been used in the treatment of this condition. Coutts ${ }^{7}$ favours neo-arsphenamine for those cases, often accompanied by so-called abacterial pyuria, in which a spirochaete has been found. This variety appears to be relatively uncommon in Great Britain and, in any event, the arsphenamines are best avoided when possible now that less toxic drugs are available. The sulphonamides are fairly successful and deserve a trial, although they seldom cause a non-gonococcal discharge to dry up in the same sudden and complete manner as an acute gonorrhoea: Penicillin is usually ineffective.

The results of treatment with streptomycin are often better although the numbers of published cases are small, ${ }^{2639}$ and these are not wholly satisfying. Aureomycin, ${ }^{52}$ chloramphenicol ${ }^{6}$ and terramycin ${ }^{11}$ are more effective and doubtless, when these now expensive drugs are more readily available, they will become the drugs of choice.

The recommended dose of streptomycin is I gm. once or preferably twice daily for five days. With the oral antibiotics two $250 \mathrm{mg}$. capsules taken four times daily for two days, followed by one capsule four times daily for four days (total $8 \mathrm{gm}$.) is a satisfactory course.

Two warnings should, however, be given: (I) The oral antibiotics are also effective against gonorrhoea and, if they are employed indiscriminately in all cases of urethral discharge, will usually effectively cure both diseases. Although gonorrhoea in the adult male is nearly always venereally acquired, there are a number of cases in which this cannot be fairly said for non-specific urethritis: and the venereologist never knows when he may be called to give evidence in the divorce court. If, therefore, the practitioner intends to treat the patient himself, or give preliminary treatment prior to reference to a clinic which may be open only once or twice a week, he should first take a urethral smear. Should the patient be referred to hospital for post-treatment tests then the smear may be sent with him. (2) An occasional cause of non-specific urethritis is intraurethral chancre. The diagnosis is nearly always betrayed by the characteristic enlargement of the inguinal glands, although it is surprising how often these comparatively uncommon cases are missed owing to the omission of the elementary precaution of dropping the trousers at the time of examina- 
tion. As these drugs all have a potent action upon syphilis, the perhaps inadequate doses given for urethritis might have serious later consequences if this condition was due to intraurethral chancre.

All cases of non-specific urethritis treated with the antibiotics should have the same follow-up as patients with gonorrhoea.

\section{Soft Sore (Chancroid)}

This complaint, due to $H$. ducreyi, responds to the sulphonamides, penicillin, streptomycin, aureomycin, chloramphenicol and terramycin.

Sulphonamides, in doses of 4-5 g. daily for five to seven days, are definitely preferred, as they have no effect upon a syphilitic infection which may mimic chancroid or accompany it. As the approach to this condition is to exclude syphilis by three daily dark-field examinations of material from the sores, followed by serum tests once a month for three months, with the object of being able positively to assure the patient at the end of this time that he is not suffering from the more serious disease, none of the antibiotics are recommended as a routine as they would influence a syphilitic infection if present. If they are used, then the patient should have the full follow-up for two years, with repeated serum tests and a cerebrospinal fluid examination at the end of this time, just in case the condition was syphilitic after all. Such a prolonged inconvenience is to be avoided for a relatively trivial condition as chancroid.

Soft sore may be accompanied by inguinal buboes which may break down and result in chancroidal ulceration in the groins, or it may be complicated by phagedoena in which case there may be gross tissue destruction. In those cases, therefore, in which threatened loss of the member exceeds the risks of masking syphilis, the antibiotics should be used.

It is interesting to observe that Wetherbee et al..$^{37}$ tried a number of antibiotics against $H$. ducreyi in vitro and came to the conclusion that streptomycin, previously successfully tried in man, ${ }^{17}$ was the only one likely to be effective. This has since been disproved. The writer 4648 performed inoculation experiments on some 227 volunteers, inoculating some of them with virulent bubo fluid from untreated persons, treating them with various drugs, and noting whether the experimental infection was or was not produced at the site of inoculation. In another group of patients with chancroidal buboes, fluid from which was proved to be virulent by inoculation into untreated controls, the fluid was again aspirated and inoculated into others 24 hours and more after treatment with one of the drugs had commenced. By these means it was shown that sulphonamides, streptomycin, penicillin in high doses, aureomycin and chloramphenicol were all effective, while neoarsphenamine, bismuth and antimony were not.

If the antibiotics are used, streptomycin is the one least likely to mask syphilis, although the author noted the healing of lesions with disappearance of treponemata in three cases of early syphilis given only $1.5-6.0 \mathrm{~g}$. of streptomycin over two to three days. ${ }^{45}$ The dose recommended is that given for granuloma venereum, or even smaller amounts, as I gm. twice daily for seven days, may be sufficient. If the oral antibiotics are employed the course recommended for nonspecific urethritis is adequate.

Patients treated with sulphonamides should be followed up with serum tests once a month for three months. The period of surveillance should be extended to six months for those patients treated with antibiotics. The insistence on such a follow-up is only feasible in well-developed communities. In places where it is not feasible, e.g. tropical Africa, where diagnostic facilities are often absent, it is justifiable to treat all patients with penile sore as for syphilis, adding sulphonamides for the few cases which prove refractory. For this purpose a single injection of 2.4 mega units of procaine penicillin $G$ with 2 per cent aluminium monostearate is most suitable. ${ }^{40}$

\section{Syphilis}

The older drugs used in the treatment of syphilis, iodides, mercury, bismuth and the arsphenamines, have all had their day and are now fading from the scene. France, particularly, releases them less readily and the French influence is felt in many parts of the world, especially the Near East as in Turkey, Lebanon, Syria and Egypt.

Penicillin is the best agent yet discovered. The newer antibiotics, - aureomycin, ${ }^{19} 2541$ chloramphenicol, ${ }^{31} 40$ and terramycin, ${ }^{16}$ have all been shown capable of healing the lesions of early syphilis and of reversing the serum reaction. Aureomycin has also been shown capable of healing gummata ${ }^{21}$ and of reversing abnormal spinal fluids. ${ }^{22}$ Even so, the treatment of syphilis with these drugs is only in the experimental stage and, at present, they should not be used other than experimentally. Their final position in the scheme of things, as a sole or adjuvant treatment, or in relationship with each other, has yet to be decided. In this paper, therefore, only penicillin will be considered.

\section{Early Syphilis}

Towards the end of the mercury era, with its alternation of too much and too little treatment (usually too much), it was usual to treat the 
patient with appropriate rest periods for at least one year. The same practice was followed with arsenic and bismuth once it was realized that Ehrlich's dream of curing syphilis with a single dose was not to be realized. Indeed, the French ${ }^{35}$ have defined the treatment of syphilis as: (I) The period of attack for one year; (2) the period of consolidation for two to three years; and (3) the period of insurance treatment for three to four years, followed by observation for life. Thus, in some circumstances, the treatment of syphilis has been sometimes almost as bad as the disease itself.

However, the older régimes did at least ensure that more than 90 per cent. of those that completed it were cured. Thus Thompson and Smith, ${ }^{33}$ analysing the results of 771 cases after 16 to 29 years, found 90.4 per cent. were free of the disease. Few cases, however, completed their treatment, while with penicillin practically all patients obtain the essential part. With penicillin the period of attack is reduced to only eight days, although the period of surveillance remains the same. It is the period of consolidation which is open to dispute.

Although penicillin was discovered in Britain its exploitation has been more successfully pursued in the U.S.A. The first schedule to be employed for syphilis consisted of $\mathbf{2 . 4}$ mega units given over $7 \frac{1}{2}$ days, but the varying and equivocal results later obtained led to the realization that penicillin contained a number of fractions ( $G, F, X$ and $K$ ), of which the $\mathrm{G}$ fraction is the most potent against syphilis.

In a short time crystalline penicillin $G$ was purified and used as a routine in the treatment of syphilis with greatly improved results. The original method of giving the injections every two to four hours was replaced by single daily injections of a delayed-absorption preparation such as penicillin in oil-beeswax (POB-Romansky formula $\left.{ }^{30}\right)$. The standard course of penicillin then consisted of eight daily injections of penicillin in oil-beeswax, although this substance was not always easy to administer. It has now been replaced by procaine penicillin $G$ with 2 per cent. aluminium monostearate (PAM). It was found that procaine and penicillin combined together to form a substance which was more slowly absorbed. When procaine penicillin is suspended in arachis oil and gelled with 2 per cent. aluminium monostearate even more prolonged serum levels can be obtained, and eight daily injections of 600,000 units of PAM are now widely employed for early syphilis.

Actually a ' single' injection of 2.4 mega units of PAM ( $4 \mathrm{ml}$. in each buttock) will maintain a blood level for a week or more ${ }^{4054}$ and the cure of syphilis by a single injection is possible. Ehrlich's dream is realized. This is not a thoroughly satisfactory treatment for the individual, although only ro per cent. of failures were noted after I 5 months in consolidated figures of the United States Public Health Service. ${ }^{3}$ Its greatest potentialities, however, are for mass treatment campaigns in medically undeveloped areas, in which the main object is not to guarantee a cure for the individual but to reduce the incidence of infective lesions in the masses. The writer has used this method with success in Africa, and W.H.O. are employing it in Haiti and Indonesia for yaws, and in Iraq for bojel. Syphilis of primitive races is frequently of the bejel type; non-venereal and spread by close contact, dirt, overcrowding, flies and the communal drinking bowl. The writer found another variety, the njovera, in Southern Rhodesia. ${ }^{51}$ 'Single shot' methods are most valuable in such circumstances, ${ }^{50}$ but are not recommended for those countries in which the best possible treatment of the individual is practised.

In this country we never abandoned entirely the use of the more prolonged treatments but effected the traditional British compromise and combined one course of neo-arsphenamine and bismuth with 4.0-4.8 mega units of penicillin.

It has been noted that cases in the secondary stage, which comprise about one-third of the males and two-thirds of the female cases of early syphilis, fare less well than those of primary, especially sero-negative primary syphilis. The failure rate for secondary cases at two years with the old 2.4 mega units of commercial penicillin alone has been assessed at 35 per cent. ${ }^{1}$ With crystalline penicillin $G$ it was substantially reduced to 12 per cent. $^{3}$

However pleased we have been in this country with the results of a schedule consisting of 4.8 mega units of penicillin over eight days plus 5.5-6.o g. of neoarsphenamine and $2 \mathrm{~g}$. of bismuth over ro weeks, the toxic complications of dermatitis, agranulocytosis, and encephalopathy-not to forget the added risk of syringe-transmitted jaundice when intravenous injections are givencaused many clinicians to drop the arsenic and give only penicillin and bismuth. ${ }^{20}{ }^{23}$

Unfortunately we have no central statistical unit in Great Britain which can produce co-operative figures of our own results. Some cooperative data is, however, forthcoming as a result of the action of the W.H.O. who, rightly concentrating on the results of treatment of secondary syphilis, have obtained and combined data from two London clinics. It is hoped that in the future we will continue to produce such figures for ourselves, for this basic 
feature of clinical research has maintained for so long the American lead in venereal disease affairs.

The W.H.O. analysis is most interesting and has been presented by Guthe and Reynolds. ${ }^{14}$ The British figures concerning penicillin, neoarsphenamine and bismuth, and penicillin and bismuth only, are contrasted with those of PAM alone in America. The cumulative retreatment rate at two years is considered to be 14.5 per cent. with penicillin alone, 13:6 per cent. with penicillin and bismuth, and only 5.4 per cent. with penicillin, arsenic and bismuth. On the other hand, the percentage of serious reactions was only 0.12 with penicillin alone, 0.91 with penicillin and bismuth and 9.55 with penicillin, arsenic and bismuth. Moreover, the percentages of patients completing treatment with the three groups respectively was $96.8,83.2$ and 69.8 per cent. (although it must be admitted that the numbers completing the penicillin course must have been approximately equal in all groups).

A statistical examination of the above indicates that the differences between the toxicity and default rates of the different groups are significant. Those between the efficacy of penicillin and bismuth, and penicillin, arsenic and bismuth, are not; and one awaits eagerly the collection of more data. It thus appears that any possible superior results of combining arsenic and bismuth with penicillin are offset by the increased default rate and the added risk of toxic complications. Trials are now in progress at St. Mary's giving weekly injections of $600,000-900,000$ units of penicillin for to weeks following the same penicillin course of eight daily injections of 600,000 units, and this probably represents a good standard treatment for early syphilis. This is followed by serum tests once a month for six months, once a quarter for a year, half-yearly for a further year, with a cerebrospinal fluid examination at the end of that time. Relapses may be treated as before, perhaps with the addition of bismuth and/or arsenic.

\section{Late Syphilis}

Late syphilis consists of late latent syphilis, benign (gummatous) late syphilis, cardiovascular syphilis and neurosyphilis. Information concerning the results of the treatment with penicillin of benign late syphilis and neurosyphilis is to hand, but it is still difficult to evaluate the results in late latent and cardiovascular syphilis, as insufficient time has elapsed as to make this possible.

In the old days neoarsphenamine and bismuth, given over a period of at least one year, was a satisfactory form of treatment for late syphilis, although in neurosyphilis tryparsamide was often substituted for neoarsphenamine, and fever by malaria or hypertherm given in addition. Since penicillin was introduced it has been the practice in this country after its use to continue treatment for six months with arsenic and bismuth; although latterly, in some clinics, a weekly dose of $600,000-$ 900,000 units of procaine penicillin has replaced the arsenic and sometimes the bismuth also, it being felt that there is little that arsenic and bismuth can accomplish that penicillin cannot do better and more safely.

Cardiovascular syphilis may be obvious or it may be concealed in cases of suspected late latent syphilis: also it may be present, either recognized or unrecognized, in neurosyphilis. In all of these circumstances there is a danger of a focal JarischHerxheimer reaction in the aorta if competent spirochetocidal drugs (e.g. penicillin, arsphenamines and oral antibiotics) are suddenly used. Similar focal reactions may occur in other parts of the body in other forms of late syphilis. For this reason it has been the practice to commence treatment giving injections of bismuth, with or without iodides, once or twice weekly for four to six weeks. Late syphilis is seldom a medical emergency and, after this short course, penicillin may then be safely given. This perhaps is the strongest remaining indication for the retention of bismuth in the treatment of syphilis today. Hows ever it is not unlikely that the heavy metal could be replaced in this respect by the oral antibiotics given in increasing doses, but this has yet to be proved.

Incidentally a number of writers consider that the danger of therapeutic shock is over-estimated, and at least one group of workers ${ }^{9}$ have gone so far as to break a basic rule in the treatment of aortic syphilis with heart failure, viz., treat the heart failure before the syphilis, and have given penicillin and digitalis simultaneously to the previously untreated case without adverse effect. On the other hand, tragedies have indeed from time to time been reported and it seems desirable not to take unnecessary risks even if they are slight.

In the treatment of neurosyphilis malaria and fever have been combined with penicillin in a number of centres, but the view is now widely expressed that there is little to be gained by the addition of fever, which may, indeed, be dangerous in debilitated subjects. There has also been a tendency to increase the dose of penicillin from 4.8 million units to 9 million units or more, given over 15 or more consecutive days. Recent assessments by Ingraham et al., ${ }^{18}$ however, whose experience now extends over 603 cases, some of which have been observed for seven years, still suggest that the optimum dose of penicillin is in the region of 4.0-4.8 million units given over 
eight days. Although no harm can arise from giving more than this amount, there is little to be gained by doing so: the disease is either cured or is resistant from the outset. The index of improvement is the cerebrospinal fluid, which may show a spate of abnormalities in neurosyphilis. Clinical signs dependent upon breaks in neurons are unlikely to change, and the serology in treated late syphilis is usually fast.

\section{Congenital Syphilis}

The optimum time during which to cure congenital syphilis is before the child is born. This may be done in 95 per cent. of cases by a-course of eight daily injections of 600,000 units of procaine penicillin given during pregnancy. It is customary to continue treatment until term, or give two additional injections of 2.4 mega units of PAM once a week during the last two weeks, in order to insure against a possible relapse in the mother being transferred to the child. Penicillin is likewise the drug of choice in the treatment of early congenital syphilis, some 400,000 units per kg. of bodyweight being spread over Io to 15 days. Additional weekly treatment with penicillin, and /or sulpharsphenamine and bismuth which are well tolerated in the child, may be continued for six months. The follow-up should be as for early acquired syphilis in the adult.

Late congenital syphilis offers similar problems as the treatment of late syphilis in the adult. In both a lumbar puncture should be performed before treatment to exclude involvement of the central nervous system. Penicillin should be given to all and the treatment continued over a period of six months. The complications of interstitial keratitis may require fever to bring it to a standstill, but the giving of adequate treatment, and even a reversal of the blood to negativity, are no guarantees that the condition may not affect the other eye after an interval. Cortisone and ACTH have been shown to exert a profound effect upon the defence mechanisms of syphilis. $^{34}$ On stopping the drug these mechanisms revive with added activity and it has been queried whether this so-called 'rebound phenomenon' may contraindicate their use in syphilis owing to possible dire consequences upon unsuspected aortic and other buried lesions. It is probable that these drugs will be of great value in reducing the intense defence mechanisms in interstitial keratitis, which frequently lead to corneal opacities and loss of vision. If penicillin treatment precedes, or is given simultaneously with cortisone, the ' rebound phenomena' may possibly be avoided. We must await the results of further work.

Few cases of syphilis have been reported which do not respond to penicillin in sufficient doses. Every case of syphilis deserves a course of penicillin. If refractory cases are met we have more penicillin, the oral antibiotics and neoarsphenamine and bismuth held in reserve.

\section{Summary}

The indications of the various drugs at present employed in the treatment of the venereal diseases may be summarized as follows:-

\begin{tabular}{|c|c|c|c|}
\hline Disease. & First Choice. & Second Choice. & Third Choice. \\
\hline Syphilis & Penicillin & More penicillin & $\begin{array}{l}\text { Oral antibiotics } \\
\text { Neoarsphenamine } \\
\text { Bismuth }\end{array}$ \\
\hline Gonorrhoea & Penicillin & Streptomycin & $\begin{array}{l}\text { Aureomycin } \\
\text { Chloramphenicol } \\
\text { Terramycin }\end{array}$ \\
\hline Lymphogranuloma venereum & Sulphonamides & Aureomycin & Fever \\
\hline Granuloma inguinale & Chloramphenicol & Aureomycin & Streptomycin \\
\hline Soft sore (chancroid) & Sulphonamides & Streptomycin & $\begin{array}{l}\text { Oral antibiotics } \\
\text { Penicillin }\end{array}$ \\
\hline Non-specific urethritis & $\begin{array}{l}\text { Chloramphenicol } \\
\text { Terramycin } \\
\text { Aureomycin }\end{array}$ & Streptomycin & $\begin{array}{l}\text { Sulphonamides } \\
\text { Penicillin }\end{array}$ \\
\hline
\end{tabular}




\section{REFERENCES}

1. BARTON, R. L., BAUER, T. J., CRAIG, R. M., and SCHWEMLEIN, G. X.' (1949), Arch. Dermat. 'Syph. Chicago, 60, 150 .

2. BAUER, T. J. (1949), f. Vener. Dis. Inform., 30, 185.

3. BAUER, T. J., USIL'TON, L. J., and PRICE, E. V. (I950),

Ibid.3 3I, 65. E., DESTAING, F. GUTHIER; J., and SORREL, G. (I949), Bull. Soc. Méd. Hôp. Paris, 65, 832.

5. CAMPBELL, D. J. (I944), Brit. Med. F., 2, 44.

7. COUTTS, W. E., and VARGAS ZALAZAR, R. (1946), Brit. Med. $\mathcal{F}_{\text {., }}$ 2, 982 .

8. DUNLOP, E. M. C. (1949), Brit. F. Vener. Dis., 25, 81.

9. EIDEKEN, J., FORD, W. T., FALK, M. S., and STOKES, J. H. (1950), 'Circulation $\mathbf{r}_{3}, 1366$.

10. FINDLAY, G. M. (I950), 'Recent Advances in Chemotherapy,' Churchill, London.

I1. FINDLAY, G. M., and WILLCOX, R. R., unpublished work.

12. GREAVES, A. B., MACDONALD, G. R., ROMANSKY, M. J., and TAGGART, S. R. (1950), $\mathscr{f}$. Vener. Dis. Inform.,

13. GREENBLATT, R. B., WAMMOCK, V. S., CHEN, C. H., DIENST, R. B., and WEST, R. M. (1950), 甹. Vener. Dis. Inform., 3I, 45 .

14. GUTHE,'T., and REYNOLDS, F. W. (1951), World Health Organization document.

15. HARKNESS, A. H. (1950), ' Non-specific Urethritis,' Living-

stone.
16. HENDRICKS, F. D., GREAVES, A. B., OLANSKY, S., TAGGART, S. R., LEWIS, C.' N. LABNDMAN, G. S., MACDONALD, G. R., and WELCH, H. (1950), $\%$. Amer. Med. Ass., 143, 4.

17. HIRSH, H. L., and TAGGART, S. R. (1948), f. Vener. Dis. Inform., 29, 47.

18. INGRAHAM, N. R., STOKES, J. H., and GAMMON,

19. IRGANG, S., and ALEXANDER, E. R. (1948), Harlem Hosp. Bull., $\mathbf{r}, 9 \mathrm{x}$.

20. JEFFERISS, F. J. G., WILLCOX, R. R., and MCELLIGOTT, G. L. M.'(1951), Lancet, i, 83.

21. KIERLAND, R., and O'LEARY, P. (1950), Amer. F. Syph., 22. KIERLAND, R., HERRELL, W. E., and O'LEARY, P. (1950), Arch. Dermat. Syph.'Chicago,'61, 186.

23. MCELLIGOTT, G. L. M., JEFFERISS, F. J. C., and

WILLCOX, R. R. (1948), Brit. F. Vener. Dis., 24, 45.
24. MACFARLANE, W. V. (1950), Ibid., 26, 73.

25. O'LEARY, P. A., KIERLAND, R. R., and HERRELL, W. E. ('1948), Proc. Mayo Clin., 23, 574 .

26. PULASKI, E. J. (1947), $¥$. Vener. Dis. Inform., 28, I.

27. ROBINSON, R. C. V. (1950), Amer. F. Syph., 34, 64.

28. ROBINSON, R. C. V. (I950), Ibid., 34, 587 . C., and TRICE, E. R. (1950), Ibid., 34, 67. 30. ROMANSKY, M. J., and RITTMAN, G. E. (1945), New

31. ROMANSKY, M. J., OLANSKY, S., TAGGART, S. R., and ROBIN, E. D. (1949), Science, $110,639$.

32. TAGGART, S. R., PUTNAM, D. E., GREAVES, A. B., and WATSON, J. A. (1950), Amer. $\mathcal{F}$. Syph., 34, 62.

33. THOMPSON, R. C., and SMITH, D. C. (1950), Ibid., 34, 356.

34. TURNER, T. B., and HOLLANDER, D. H. (1950), Bull. fohns Hopk. Hosp., 87, 507 .

35. VEYRE, P., and BAYLET, R. (1949), Méd. Trop. Marseilles,

36. WAMMMOCK, V. S., CARROZZINO, O. M., INGRAHAM, N. R., and CLAIR, N. E. (1950), Amer. F. Obstet. Gynec., 59,606 .

37. WETHERBEE, D. G., HENKE, M. A., ANDERSON, R. I., PULASKI, E. J., and KUHNS, D. M. (1949), Amer. $\ddot{\mathscr{y}}$. Syph., 30, 352.

38. WILLCOX, R. R. (1946), Postgrad. Med. F., 22, 96.

39. WILLCOX, R. R. (1949), Lancet, i, 395 .

40. WILLCOX, R. R. (1949), Suid Afrika Tydskrif vir Geneeskunde, 23, 1040.

. WILLCOX, R. R. (1949), Med. Press, III, 585.

42. WILlCOX, R. R. (1950), Med. World., Nov., 89.

43. WILLCOX, R. R. (1950), Ұ. Roy. Army Med. Cps., 94, 167.

44. WILLCOX, R. R. (1950), Nature, 166, 466.

45. WILLCOX, R. R. (1950), Lancet, i, 396.

46. WILLCOX, R. R. (1950), Amer. 'F. Syph., 34, 378.

47. WILLCOX, R. R. (1950), Arch. Dermat. Syph. Chicago, 62, 533. 48. WILLCOX, R. R. (1950), Brit. F. Vener. Dis., 26, 131 .

49. WILLCOX, R. R. (1950), Ұ. Roy. Army Med. Cps., 94, 126.

50. WILLCOX, R. R. (1950), $\dot{\mathfrak{F}}$. Vener. Dis. Inform., 31, 254.

51. WILLCOX, R. R. (1950), ' Textbook of Venereal Diseases, Heinemann, London.

52. WILLCOX, R. R., and FINDLAY, G. M. (I949), Brit. Med. F., 2, 257.

53. WRIGHT, L. T., SANDERS, M., HOGAN, M. A., PRIGOT, 54. YOU., and,HiLL, L. M. (1948), $\mathcal{F}$. Amer. Med. Ass., 138, 408 . GOMERY, G.'M. (1949), Lancet, i, 863.

\section{RUTHIN CASTLE, NORTH WALES}

A Clinic for the diagnosis and treatment of Internal Diseases (except Mental or Infectious Diseases). The Clinic is provided with a staff of doctors, technicians and nurses.

The surroundings are beautiful. The climate is mild. There is central heating throughout. The annual rainfall is 30.5 inches, that is, less than the average for England.

The Fees are inclusive and vary according to the room occupied.

For particulars apply to THE SECRETARY, Ruthin Castle, North Wales.

Telegrams: Castle, Ruthin.

Telephone : Ruthin 66. 